\title{
Real-life effect of a microcrystalline tyrosine adjuvanted mite immunotherapy in patients with allergic rhinitis
}

\author{
Albert Roger ${ }^{1}$, Alfons Malet ${ }^{2}$, Victoria Moreno ${ }^{3}$, Antonio Parra ${ }^{4}$, Diego Gutiérrez ${ }^{5}$, Ramón \\ Lleonart $^{6}$, Francisco Moreno ${ }^{7}$, Antonio Valero ${ }^{8}$, Begoña Navarro ${ }^{9}$, Belén Hinojosa ${ }^{10}$ \& José \\ L Justicia*, 11 \\ ${ }^{1}$ Allergy Department, Hospital Germans Trias i Pujol, Badalona, Spain \\ ${ }^{2}$ Al.lergo Centre, Barcelona, Spain \\ ${ }^{3}$ Centro de Especialidades Médicas Integradas, Huelva, Spain \\ ${ }^{4}$ Allergy Department, Hospital A Coruña, A Coruña, Spain \\ ${ }^{5}$ Clínica Virgen del Rosario, Algeciras, Spain \\ ${ }^{6}$ Allergy Department, Hospital Universitari de Bellvitge, Barcelona, Spain \\ ${ }^{7}$ Clínica Dr. Lobatón, Cádiz, Spain \\ ${ }^{8}$ Pneumology and Respiratory Allergy, Hospital Clínic de Barcelona, IDIBAPS, CIBERES, Barcelona, Spain \\ ${ }^{9}$ Allergy Department, Hospital Universitari Dexeus, Barcelona, Spain \\ ${ }^{10}$ Allergy Section, Hospital Juan Ramón Jiménez, Huelva, Spain \\ ${ }^{11}$ Allergy Therapeutics Ibérica, Sant Joan Despí, Barcelona, Spain \\ *Author for correspondence: Tel.: +34 934751 390; Fax: +34 934741 534; joseluis.justicia@allergytherapeutics.com
}

\begin{abstract}
Aim: Evaluate the effectiveness and safety of immunotherapy with Acarovac Plus ${ }^{\circledR}$ in a 1-year prospective multicentered real-life study. Methods: A total of 118 adults with allergic rhinitis sensitized to Dermatophagoides received subcutaneous immunotherapy with Acarovac Plus. Treatment outcomes were evaluated at baseline, 6 months and 1 year after treatment initiation. Primary end point was the evolution of the combined symptom and medication score. Secondary end points included other effectiveness outcomes and measurement of product tolerability. Results: Acarovac Plus induced significant improvements in primary and secondary end points after 6 months compared with baseline. These differences persisted after 1 year of treatment ( $p<0.001$; baseline vs 1 year): combined symptom and medication score (1.60 vs 0.79 ). No serious adverse events were recorded. Conclusion: Acarovac Plus for 1 year was effective and well tolerated in a real-life setting.
\end{abstract}

First draft submitted: 14 November 2019; Accepted for publication: 6 December 2019; Published online: 8 January 2020

Keywords: Dermatophagoides pteronyssinus $\bullet$ adjuvants $\bullet$ allergic rhinitis $\bullet$ effectiveness $\bullet$ house dust mites $\bullet$ reallife clinical practice $\bullet$ safety $\bullet$ subcutaneous allergen immunotherapy

Allergic rhinitis (AR) is a highly prevalent allergic disease and one of the most frequent reasons for medical consultation [1]. Sensitization to house dust mite airborne allergens is recognized as a causative factor for both AR and allergic asthma [2]. Among all dust mites, the prevalence of sensitization to Dermatophagoides pteronyssinus (D. pter.) is the most common [3]. Avoidance of house dust mites is not always feasible, and patients worldwide are suffering rhinitis symptoms such as runny nose, watery eyes, sneezing or nasal congestion that have a great impact on their daily life.

Traditional pharmacotherapy with antihistamines or corticosteroids provides symptomatic relief but does not offer long-term benefits, since the natural progression of the disease remains unaffected. Despite abundant treatment options, many patients are not satisfied because those therapies are not always sufficient to control the symptoms, especially in cases of moderate or severe allergic disease, or patients with concomitant allergic asthma $[4,5]$. In these cases, treatment with specific immunotherapy is indicated.

Allergen-specific immunotherapy consists of administering the specific allergen to an allergic person in order to increase their immunological tolerance and to decrease the symptoms associated with subsequent exposure to 
the causative allergen. This therapy addresses the immune cause of the disease, and today it is the only treatment modality that, as recognized by the World Health Organization, in addition to effectively reducing allergic symptoms and the need for symptomatic medication, also has the potential to alter the natural course of the disease [6].

Acarovac Plus ${ }^{\circledR}$ is a purified allergen extract from D. pter. modified into an allergoid by treatment with glutaraldehyde and adjuvanted with microcrystalline tyrosine (MCT). Previous studies demonstrated the clinical and immunological efficacy and tolerability in a small-size, single-center, observational study $[7,8]$.

The aim of the present study was to extend the analysis of the effectiveness of immunotherapy with a $D$. pter. extract modified with glutaraldehyde and associated with MCT (Acarovac Plus) and to determine its tolerability in adult patients with AR in a multicenter real-life setting.

\section{Materials \& methods}

Study design

We performed a prospective, multicenter observational study, including adult patients with AR, with or without asthma, caused by hypersensitivity to $D$. pter. who were eligible for treatment with specific immunotherapy according to standard clinical practice.

This study was approved by the Ethics Committee of the Hospital Germans Trias i Pujol (Ref. EPA-14-023) and met the ethical principles stated in the Declaration of Helsinki. Written informed consent was obtained from all individual participants included in the study.

\section{Participants}

The study population consisted of adult patients aged between 18 and 65 years, with AR with or without asthma secondary to hypersensitivity to $D$. pter. Diagnosis of AR was made on basis of patients' clinical history and physical examination.

Other inclusion criteria were as follows: clinical symptoms of AR caused by $D$. pter. for at least 1 year before study initiation and for whom, in the investigator's opinion, treatment with specific immunotherapy was indicated; skin prick test result $\geq 3 \mathrm{~mm}$ in diameter for $D$. pter. in the previous 12 months; positive result for a specific $\operatorname{IgE}$ to $D$. pter. of at least class 2 (greater than $0.7 \mathrm{kU} / 1$ measured by ImmunoCAP system; Thermo Fisher Scientific, Waltham, MA, USA) at baseline; patients monosensitized to Dermatophagoides or polysensitized, provided that, in the investigator's opinion, the other sensitizations were not clinically relevant; the specialist prescribed Acarovac Plus D. pter. Patients that presented sensitization to other clinically relevant perennial and seasonal allergens, except for other mites, who had received previous immunotherapy for the allergen being tested or presented any of the medical or social conditions listed in the Supplementary Information were excluded.

\section{Immunotherapy}

Acarovac Plus (Allergy Therapeutics, Worthing, UK), an extract of $D$. pter. modified into allergoid by treatment with glutaraldehyde and associated with MCT as an adjuvant, was subcutaneously injected with increasing doses in the initial phase, starting with $0.05 \mathrm{ml}$. Subsequent doses, administered with an interval of 1-2 weeks between injections increase until reaching $0.5 \mathrm{ml}$ in these steps: $0.05,0.1,0.3 \mathrm{ml}$. The treatment continued with injections of $0.5 \mathrm{ml}$ every 6 weeks until the end of treatment (dose escalation scheme is shown in Supplementary Table 1). The total duration of the study was 13 months.

\section{Definition of study outcomes}

The primary end point was the mean change in the combined symptom and medication score (CSMS, 0-6 point scale, Supplementary Table 2), as described by the European Academy of Allergy and Clinical Immunology [9], collected for 4 weeks at baseline and after 6 months and 1 year of treatment. The following effectiveness variables were also collected at baseline and 6 and 12 months: mean change in symptom score (daily symptom score) and mean change in medication consumption score (daily medication score); percentage of 'well and bad days' [9]; evolution of rhinitis control following the criteria of the American Academy of Allergy Asthma \& Immunology and the American College of Allergy, Asthma \& Immunology [10]; percentage of seriousness in the classification of rhinitis (ARIA guideline) [2]. Changes in the sensitivity to $D$. pter., as determined by using specific nasal provocation test (NPT), were assessed at baseline and at the end of the study [11]. 


\begin{tabular}{|lll|}
\hline Table 1. Patients characteristics at baseline. & & \\
\hline Variables & $n=118$ & Percentage (\%) \\
\hline Gender & 51 & \\
\hline Male & 67 & 53.2 \\
\hline Female & & \\
\hline Age & & \\
\hline Allergy history & 118 & 33.6 (9.55) \\
\hline Rhinitis & 55 & 100 \\
\hline Asthma & 46.6 \\
\hline Previous immunotherapy & 2 & 1.7 \\
\hline Allergic medication for rhinitis & 103 & 87.3 \\
\hline Oral antihistamines & 92 & 89.3 \\
\hline Topical antihistamines & 7 & 6.8 \\
\hline Nasal corticosteroids & 71 & 68.9 \\
\hline Oral corticosteroids & 2 & 1.9 \\
\hline
\end{tabular}

Additionally, the mean change in intensity of symptoms using a visual analog scale (VAS) was evaluated by the patients, who also filled the ESPRINT-15 questionnaire [12] and TSQM-14 questionnaire [13] to measure changes in their quality of life and treatment satisfaction, respectively.

The number, intensity and seriousness of adverse reactions to the treatment were recorded throughout the study.

\section{Nasal provocation test}

The NPT was carried out as described previously [8] following SEAIC guidelines [11]. An extended description can be found in Supplementary Information and Supplementary Table 3.

\section{Concomitant antiallergic medication}

During treatment, patients could experience symptoms of rhinitis and/or asthma that needed additional treatment. Antihistamines, nasal corticosteroids and oral corticosteroids were used in a stepwise manner if necessary, according to usual clinical practice. In order to avoid interference with the skin tests and the NPT, washing out periods of the rescue medications were established: 3 days after antihistamines and nasal corticosteroids for a NPT, and 5 days after antihistamines for skin prick test.

\section{Statistical analysis}

Categorical variables have been described using absolute and relative frequencies (\%). Continuous variables have been described using the mean and standard deviation.

To compare patient subgroups with quantitative variables, nonparametric (Mann-Whitney and Kruskal-Wallis) tests have been used. To compare the data between visits, non parametric (Wilcoxon or Friedman) tests have been performed. Qualitative variables were calculated using the $\chi^{2}$ test or McNemar's test. The statistical analysis was performed using the SAS statistical package, version 9.4.

The calculation of the sample size has been established in accordance with ICH guidelines, which specify that the number of patients should be enough to provide a valid response regarding the issues raised. Considering that the primary end point of the study was the mean change in the CSMS at 12 months of follow-up, and the standard deviation from the mean change in CSMS was estimated to be 7.3 from a previous study (Stelmach I et al. [14]), a sample size of 142 patients would provide a precision of \pm 1.2 points for estimating the mean change in the combined symptom and drug-consumption score, with a 95\% CI. Assuming that $10 \%$ of cases could not be analyzed due to losses, the number of patients to be enrolled amounts to 150 . The calculations were made by the PASS Sample Size software (PASS 11; NCSS, LLC).

\section{Results}

\section{Study population}

As shown in Figure 1, 141 patients were initially recruited, of which 118 met the selection criteria and were included in the study for evaluation. Demographic, clinical and other patient characteristics are summarized in Table 1. 


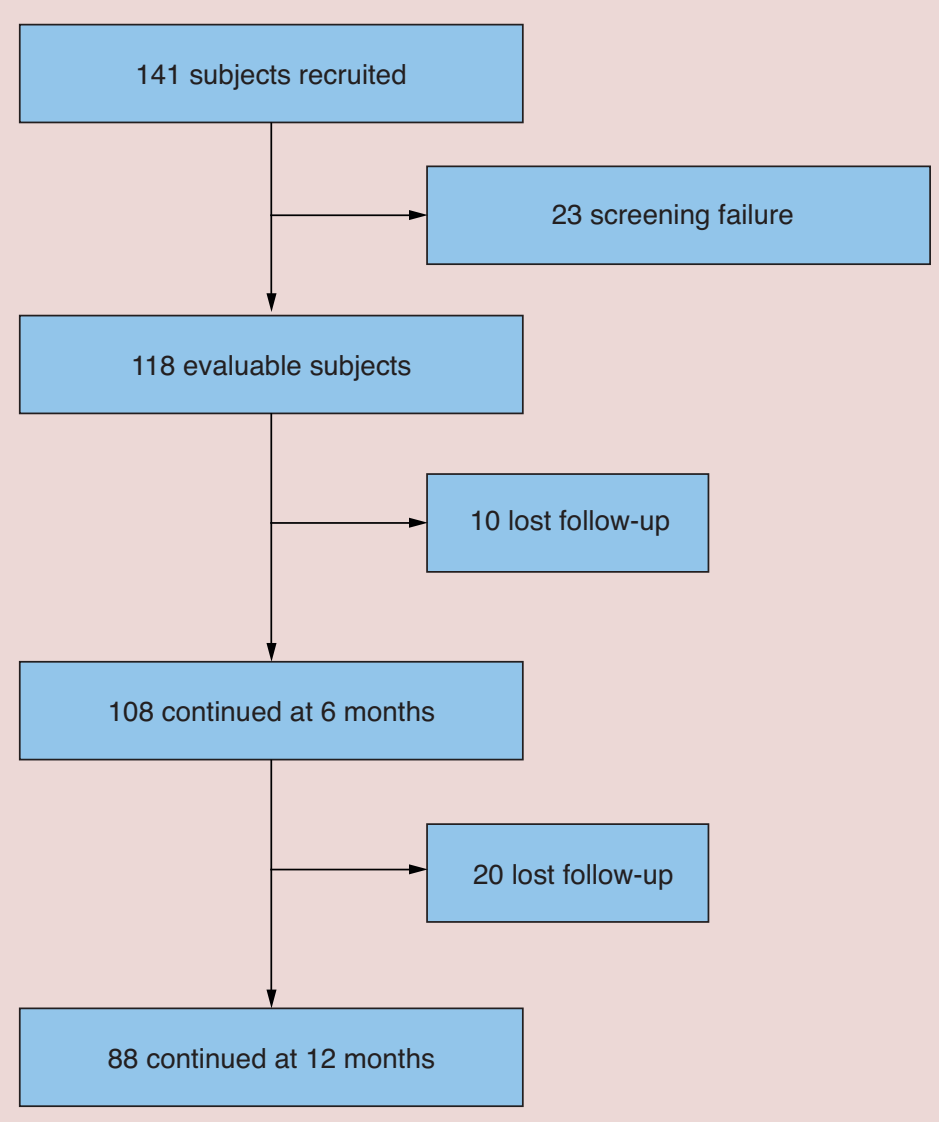

Figure 1. Study flow.

\section{Table 2. Change in combined symptom and medication score}

\begin{tabular}{|c|c|c|c|c|c|}
\hline & Visit & $n$ & Mean & SD & p-value ${ }^{\dagger}$ \\
\hline \multirow[t]{3}{*}{ CSMS (0-6) } & Baseline & 103 & 1.60 & 1.01 & \\
\hline & After 6-months IT & 88 & 1.10 & 0.98 & \\
\hline & After 1-year IT & 78 & 0.79 & 0.91 & \\
\hline \multirow[t]{3}{*}{ Change CSMS } & After 6-months IT - Baseline & 86 & -0.44 & 0.91 & $<0.0001$ \\
\hline & After 1-year IT - Baseline & 76 & -0.69 & 1.14 & $<0.0001$ \\
\hline & After 1-year IT - After 6 months IT & 77 & -0.29 & 1.00 & 0.0026 \\
\hline
\end{tabular}

†Wilcoxon test.

CSMS: Combined symptom and medication score; IT: Immunotherapy.

67 patients $(56.8 \%)$ were female. The mean age was 33.6 years $(\mathrm{SD}=9.55)$. Regarding preceding treatments with immunotherapy, only two $(1.7 \%)$ of the patients had previously received other vaccines, one $(0.85 \%)$ of which was for mite allergy. Oral antihistamines and nasal corticosteroids were the most frequently allergy medications prescribed to patients during the study ( 89.3 and $68.9 \%$ of the patients at baseline, respectively).

Change of the combined symptom \& medication score with the treatment

A mean decrease of 0.44 points $(S D=0.91)$ was obtained in CSMS between baseline and 6 months after medication treatment $(\mathrm{p}<0.0001)$, and $0.69(\mathrm{SD}=1.14)$ between baseline and 1 year after medication treatment $(\mathrm{p}<0.0001)$ (Table 2). Statistically significant mean decrease differences were also detected from 6 months to 1 year of medication 


\begin{tabular}{|c|c|c|c|c|c|}
\hline & Visit & $n$ & Mean & SD & p-value ${ }^{\dagger}$ \\
\hline \multicolumn{6}{|l|}{ Change in number of well days } \\
\hline \multirow[t]{3}{*}{ Total \% of well days $\ddagger$} & Baseline & 107 & 46.36 & 36.77 & \\
\hline & After 6-months IT & 96 & 59.67 & 39.02 & \\
\hline & After 1-year IT & 84 & 65.48 & 34.21 & \\
\hline \multirow[t]{3}{*}{ Change in the $\%$ of well days } & After 6-months IT - Baseline & 96 & 10.86 & 39.82 & 0.0031 \\
\hline & After 1-year IT - Baseline & 84 & 15.05 & 43.59 & 0.0012 \\
\hline & After 1-year IT - After 6 months IT & 84 & 2.17 & 39.74 & 0.7658 \\
\hline \multicolumn{6}{|l|}{ Change in number of bad days } \\
\hline \multirow[t]{3}{*}{ Total $\%$ of bad days $\ddagger$} & Baseline & 105 & 15.03 & 23.62 & \\
\hline & After 6-months IT & 90 & 7.22 & 16.98 & \\
\hline & After 1-year IT & 80 & 7.14 & 19.54 & \\
\hline \multirow[t]{3}{*}{ Change in the $\%$ of bad days } & After 6-months IT - Baseline & 89 & -5.50 & 17.56 & 0.0005 \\
\hline & After 1-year IT - Baseline & 79 & -3.75 & 22.82 & 0.0172 \\
\hline & After 1-year IT - After 6 months IT & 79 & 0.23 & 15.18 & 0.5700 \\
\hline \multicolumn{6}{|l|}{ Nasal provocation test } \\
\hline \multirow[t]{3}{*}{$\%$ NIPF drop and change } & Baseline (positive) & 104 & 37.38 & 22.42 & \\
\hline & $\begin{array}{l}\text { After 1-year IT (at the same concentration } \\
\text { as baseline visit) }\end{array}$ & 54 & 24.53 & 22.90 & \\
\hline & NIPF change & 54 & -12.42 & 34.26 & 0.0076 \\
\hline \multirow[t]{3}{*}{ Difference score and change } & Baseline (positive) & 106 & 6.02 & 1.94 & \\
\hline & $\begin{array}{l}\text { After 1-year IT (at the same concentration } \\
\text { as baseline visit) }\end{array}$ & 55 & 4.16 & 2.50 & \\
\hline & Change & 55 & -2.16 & 2.66 & $<0.0001$ \\
\hline \multicolumn{6}{|c|}{$\begin{array}{l}\text { Well days: days without intake of rescue medication and a symptom score below } 2 \text { [9]. Bad d } \\
\text { †Wilcoxon test. } \\
\text { ¥The calculation of the percentage has been made over a total of } 28 \text { days before each visit. } \\
\text { IT: Immunotherapy; NIPF: Nasal inspiration peak flow. }\end{array}$} \\
\hline
\end{tabular}

treatment $(\mathrm{p}=0.0026)$. Both daily-symptom score and mean daily-medication score showed a statistically significant decrease after 6 months and 1 year of treatment compared with baseline too (Supplementary Table 4).

\section{Additional efficacy outcomes}

Secondary end points regarding efficacy of the immunotherapy are shown in Table 3. Percentage of well days was significantly increased after 6 months $(59.67 \pm 39.02)$ and after 1 year $(65.48 \pm 34.21)$ of treatment versus baseline visit $(46.36 \pm 36.77)$. At the same time, the percentage of bad days decreased at follow-up visits $(7.22 \pm 16.98$ at 6 months, and $7.14 \pm 19.54$ at 1 year) compared with baseline visit $(15.03 \pm 23.62)$.

According to American Academy of Allergy Asthma \& Immunology/American College of Allergy, Asthma \& Immunology criteria, the degree of rhinitis control was improved after each visit as shown in Figure 2. At baseline, $7.6 \%$ of patients had controlled rhinitis. The percentage increased to $45.7 \%$ of patients after 6 months of treatment ( $\mathrm{p}<0.0001$ in respect to baseline visit), and to $63.1 \%$ of patients at 1 -year visit ( $\mathrm{p}<0.0001$ in respect to baseline visit and $\mathrm{p}=0.0159$ in respect to visit at 6 months). At the end of specific immunotherapy, only $2.4 \%$ of patients could not control their rhinitis. Similar results were obtained following ARIA guidelines (Supplementary Table 5). The number of patients with persistent AR decreased from $79.7 \%$ at the baseline visit to $15.5 \%$ at 1 -year visit $(\mathrm{p}<$ 0.0001). Symptom intensity was also reduced after the immunotherapy. Moderate-severe AR intensity was found in $83.1 \%$ of the evaluable patients at baseline visit versus $20.2 \%$ at 1 -year visit $(\mathrm{p}<0.0001)$.

We found a decrease in patient sensitivity to D. pter. after immunotherapy in the NPT (Table 3). The mean \% nasal inspiration peak flow drop before the treatment was $37.38 \%(\mathrm{SD}=22.42)$ and $24.53 \%(\mathrm{SD}=22.90)$ after 1 year of treatment (at the same concentration that was positive at the baseline visit) with an observed absolute mean change of $-12.42 \%(S D=34.26 ; \mathrm{p}=0.0076)$. Statistically significant differences were detected in the evolution of symptom score on nasal challenge test $(\mathrm{p}<0.0001)$ where a mean change of $-2.16(\mathrm{SD}=2.66)$ was observed between baseline visit and the visit at 1 year of treatment. 


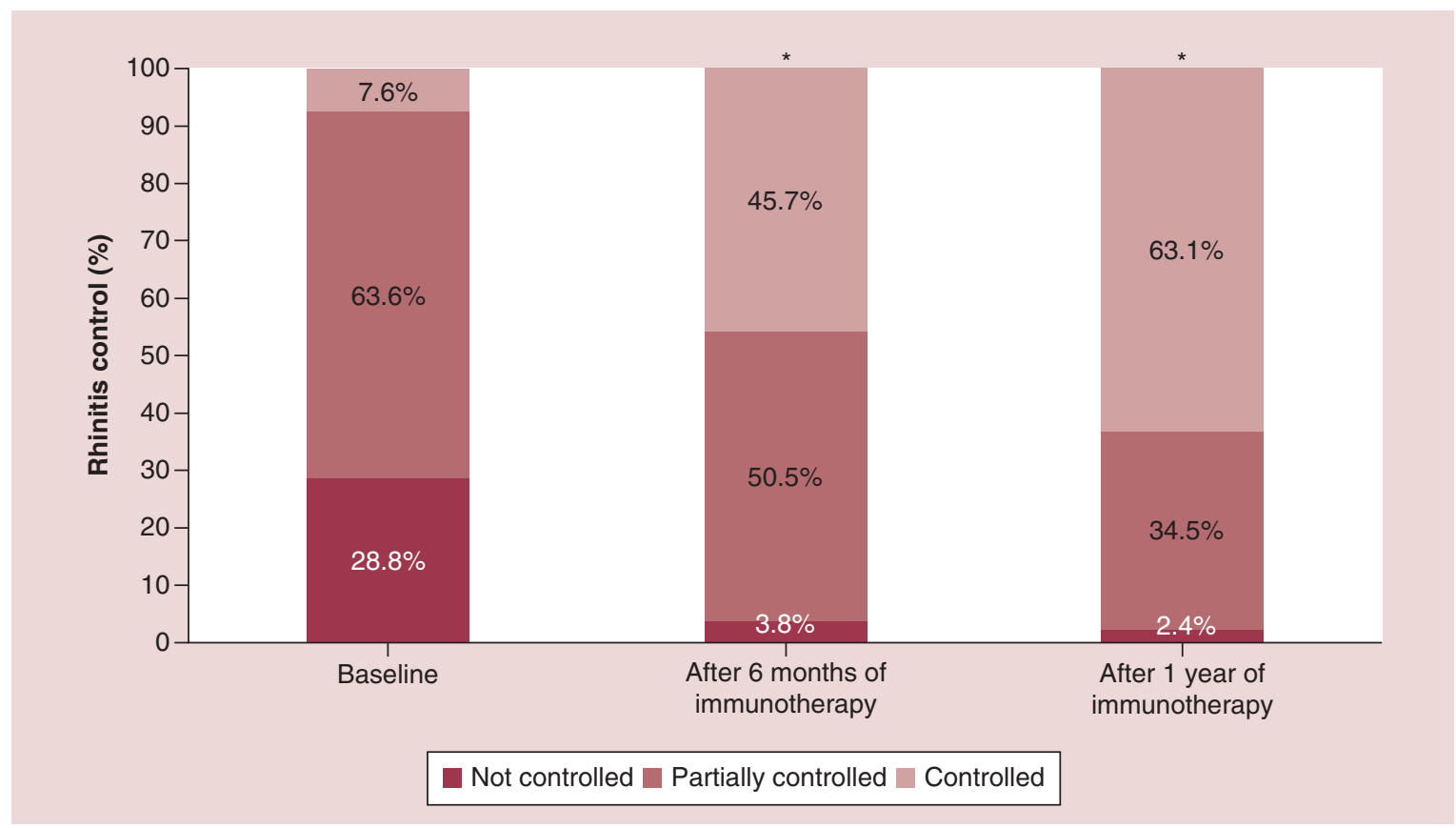

Figure 2. Degree of rhinitis control according to American Academy of Allergy Asthma \& Immunology/American College of Allergy, Asthma \& Immunology guidelines.

${ }^{*} p<0.0001$ (McNemar test) versus basal. Controlled rhinitis: does not interfere with everyday activities; $<2$ days/week: sneezing, itching, congestion, ocular symptoms. Partially controlled rhinitis: some interference with everyday activities; 2-6 days/week: sneezing, itching, congestion, ocular symptoms. Not controlled rhinitis: high degree of interference with everyday activities; daily sneezing, itching, congestion, ocular symptoms.

\begin{tabular}{|c|c|c|c|c|c|}
\hline & Visit & $n$ & Mean & SD & p-value ${ }^{\dagger}$ \\
\hline \multicolumn{6}{|c|}{ ESPRINT-15: Quality of life questionnaire } \\
\hline \multirow[t]{3}{*}{ Overall score ESPRINT-15 } & Baseline & 111 & 2.62 & 1.56 & \\
\hline & After 6-months IT & 95 & 1.33 & 1.05 & \\
\hline & After 1-year IT & 82 & 1.16 & 1.25 & \\
\hline \multirow[t]{2}{*}{ Change overall score ESPRINT-15 } & After 6-months IT - Baseline & 94 & -1.30 & 1.56 & $<0.0001$ \\
\hline & After 1-year IT - Baseline & 80 & -1.29 & 1.59 & $<0.0001$ \\
\hline \multicolumn{6}{|c|}{ TSQM: Questionnaire on treatment satisfaction 0-100 scale } \\
\hline \multirow[t]{2}{*}{ Global satisfaction } & After 6 months IT & 98 & 71.65 & 16.80 & \\
\hline & After 1-year IT & 83 & 73.41 & 18.58 & \\
\hline
\end{tabular}

VAS (scale $0-10 \mathrm{~cm}$ ) was used by the patients to evaluate symptom intensity. A mean change decrease in the VAS in respect to baseline visit of $-2.98(S D=2.96) \mathrm{cm}$ at the 6 months visit $(\mathrm{p}<0.0001)$, and $-3.55(S D=2.89)$ $\mathrm{cm}$ at 1 -year visit $(\mathrm{p}<0.0001)$ was observed (Supplementary Table 6).

Changes in patients' quality of life and treatment satisfaction were measured by the ESPRINT-15 and TSQM questionnaires as shown in Table 4. Statistically significant differences were detected in all the score dimensions of ESPRINT-15 (symptoms, daily activities, sleep and psychological impact) and total score ESPRINT-15 during the study in respect to the baseline value. A mean decrease of 1.30 ( $\mathrm{SD}=1.56)$ points was obtained in overall score ESPRINT-15 (scale 0-6) between baseline and 6 months after immunotherapy ( $p<0.0001$ ), and 1.29 (SD $=21.59)$ between baseline and 1 year after immunotherapy $(\mathrm{p}<0.0001)$. The mean global satisfaction with the treatment (TSQM, score 0-100) was high after 6 months of treatment (71.65 \pm 16.80$)$ and after 12 months of treatment (73.41 \pm 18.58$)$. 


\section{Safety outcomes}

18 patients (15.3\%) showed 87 adverse reactions. They were mostly local (95.4\%), and only four mild systemic reactions were reported. Those included a 24 -year-old male patient that suffered a systemic reaction consisting of discomfort and headache on two separate occasions, $24 \mathrm{~h}$ after the maintenance dose was administered $(0.5 \mathrm{ml})$. These reactions disappeared spontaneously at $48 \mathrm{~h}$. The causal relationship was classified as 'possible' by the investigator. No deaths or serious adverse events were recorded. Supplementary Table 7 provides a summary of the safety end points assessed throughout the study.

\section{Discussion}

The present study demonstrated that Acarovac Plus, a marketed mite-allergoid immunotherapy adjuvanted with MCT, is an effective and safe treatment for adult patients with AR. The primary end point was met, with reduction of allergic symptoms and reduction of the medication needed to alleviate symptoms of allergy after 6 months and 12 months of treatment. Importantly, other effectiveness variables such as symptom intensity, level of rhinitis control, percentage of well/bad days and nasal provocation test were also significantly improved, and no serious adverse events were reported. Moreover, patients reported a positive impact of the treatment in their quality of life and a high degree of satisfaction with the treatment.

Allergens for specific immunotherapy are often coadministered along with adjuvants to increase the allergen immunogenicity and to modulate the immune response. Aluminum hydroxide is the most commonly used adjuvant for vaccines. However, there are still concerns associated with aluminum use and its accumulation in longterm therapy [15]. Instead, Acarovac Plus is combined with MCT, a biodegradable adjuvant with high adsorption capacity [16] and a half-life of $48 \mathrm{~h}$ [17], making MCT an optimal adjuvant to modulate and enhance the immune response.

Immunotherapy is an alternative to conventional pharmacotherapy in the treatment of AR. Instead of a palliative effect, allergen immunotherapy aims to alter the normal progression of allergic diseases and could represent a cure for AR. In fact, many randomized clinical trials and meta-analyses have robustly demonstrated that immunotherapy is clinically effective in reducing the symptoms and medication consumption in respiratory allergy [18-24]. Nevertheless, real-life studies offer the opportunity of obtaining outcomes suitable in clinical practice, as controlled trials do not mirror the real patients' population observed in clinical practice [25]. In this real-life noninterventional study, we have found that treatment with Acarovac Plus reduces both the allergic symptoms and the medication needed to ease the AR, with a CSMS mean decrease of 0.69 points (a $43 \%$ reduction compared with baseline) after 1 year of immunotherapy. The observed treatment effect exceeds the results of many immunotherapy randomized controlled trials (with CSMS reductions of up to 26\% [18]) and the recommendations of the World Allergy Organization regarding the 'minimal clinically relevant efficacy' of $20 \%$ in immunotherapy clinical trials [26]. Moreover, this decrease in CSMS was accompanied by a significant improvement in other allergy outcomes, such as percentage of well days (65.48\% after 1 year of Acarovac Plus treatment vs $46.36 \%$ at baseline) and degree of rhinitis control, with $63.1 \%$ of patients reporting controlled AR after 1-year immunotherapy treatment compared with $7.6 \%$ at baseline.

The burden of AR goes beyond clinical symptoms affecting patients' quality of life. People with AR experience negative impacts on sleep, social life and their daily activities, affecting patients' performance at work [27-29]. A cross-sectional study found that AR patients experience a higher negative impact on daily activities than patients with hypertension or diabetes mellitus [30]. Accordingly, the GA2LEN group together with the European Academy of Allergy and Clinical Immunology have estimated that AR is generating more than 100 billion euros of losses per annum due to decreased work productivity associated with the pathology [31]. However, there is very limited data regarding quality of life of AR patients in a real-life setting. Our study showed that Acarovac Plus treatment enhanced patients' health-related quality of life in all the dimensions measured by the ESPRINT-15 questionnaire (symptoms, daily activities, sleep and psychological impact). The overall ESPRINT-15 score (scale 0-6) was decreased by 1.29 points after 1 year of immunotherapy treatment, thus confirming the positive impact of Acarovac Plus as an enhancer of quality of life in patients receiving standard care.

No serious adverse events were recorded in our study. Only $15.3 \%$ of patients had adverse reactions, most of them (95.4\%) being local, demonstrating that Acarovac Plus is well tolerated. These data are in agreement with previous reviews and recent observational studies reporting that local reactions are common after immunotherapy treatment [32-34]. 
This study has several strengths, including its multicenter nature and the evaluation of multiple variables to assess treatment effect. Many prospective observational immunotherapy studies are based on patient's characteristics, medication data and subjective symptoms scores. Our study, however, also includes objective parameters to measure treatment effectiveness, like the NPT, a reliable method that reproduces the allergic reaction. Moreover, it is a real-life study, allowing us to determine the effect of Acarovac Plus in the general population, following standard procedures and standard of care and contributing to the growing importance of real-life studies in allergen immunotherapy [25]. However, it also has some limitations inherent to an observational study. Since it is observational, unblinded outcome assessment cannot be avoided. In addition, safety and efficacy of this treatment should also be explored in other populations (e.g., children and adolescents) and with other mite allergens ( $D$. farinae, mixture of $D$. pteronyssinus and D. farinae, Lepidoglyphus destructor or Blomia tropicalis).

The number of patients planned to be recruited for the study was 150. Finally, just 118 patients were evaluable for the analysis at baseline. Although this fewer-than-expected number of evaluable patients could have caused a low statistic power to detect differences before and after treatment, it did not happen. After 12 months of follow-up, 30 of the 118 evaluable patients were lost. Some of them could not be evaluated at 12 months because they had improved their symptoms and decided not to continue with the vaccine (data not shown). To determine whether the differences in the main variable (CSMS) measured at baseline and at 12 months could be overestimated by the number of lost patients, who could abandon the study by treatment ineffectiveness, we performed a sensitivity analysis, considering the worst scenario (no improvement): Lost patients were asigned the last available CSMS value (e.g., baseline score was assigned to patients with data not available at 6 months, and 6-month score was assigned to patients with data not available at 12 months). Once the analysis was repeated, statistically significant differences in CSMS between baseline and at 12 months of treatment (mean decrease of 0.67 points, SD 1.03; $\mathrm{p}<0.0001$ ) were shown.

The absence of a control group makes it difficult to ascertain the significance of these results. However, it is not probable that the effects observed for Acarovac Plus are exclusively due to a placebo effect, since the study includes a measure of the changes in the sensitivity to $D$. pter. by using a specific NPT, which is an objective outcome that is not depending on patient or investigators opinions. On the other hand, study results should be confirmed using a more robust design study, ideally a double-blind, placebo-controlled clinical trial.

\section{Conclusion}

In this real-life study, we demonstrate that treatment with Acarovac Plus in adult patients with AR sensitized to $D$. pter. is effective with a balanced safety and tolerance profile. Controlled trials should be performed in order to confirm these results and quantify a possible placebo effect.

\section{Summary points}

- Previous studies demonstrated the clinical and immunological efficacy and tolerability of Acarovac Plus ${ }^{\circledR}$ in a small-size, single-center, observational study.

- In a 1-year prospective multicentered real-life study, Acarovac Plus produced a significant decrease of allergic symptoms and reduction of the medication needed to alleviate symptoms of allergy after 6 months and 12 months of treatment.

- Symptom intensity, level of rhinitis control, percentage of well/bad days and nasal provocation test were significantly improved with Acarovac Plus immunotherapy.

- Patients reported a positive impact of the treatment in their quality of life (ESPRINT-15 questionnaire) and a high degree of satisfaction with the treatment (TSQM questionnaire).

- Acarovac Plus was well tolerated and no serious adverse events were reported during the 1-year follow-up period.

Supplementary data

To view the supplementary data that accompany this paper please visit the journal website at: www.futuremedicine.com/doi/sup $\mathrm{pl} / 10.2217 / \mathrm{imt}-2019-0205$

Author contributions

All named authors meet the International Committee of Medical Journal Editors (ICMJE) criteria for authorship for this article. A Roger, A Malet and JL Justicia were responsible for the analysis and interpretation of data. All authors participated in the writing and revision of the manuscript and approved the final draft. 
Financial \& competing interests disclosure

This study was funded by Allergy Therapeutics. A Roger has received payments for consultancies and lecture fees during the conduct of the study from Allergy Therapeutics, and outside the submitted work from Leti, Roxall, Hal, Stallergenes, Diater and Merck. A Valero has served as a consultant to AstraZeneca, Novartis, Sanofi and Mundipharma and received lecture fees from Chiesi, Novartis, AstraZeneca, Mundipharma and GSK. F Moreno declares that he has received payment for lectures or advisory services from AstraZeneca, Stallergenes, Alk and Allergy Therapeutics. JL Justicia reports being an employee of Allergy Therapeutics. The authors have no other relevant affiliations or financial involvement with any organization or entity with a financial interest in or financial conflict with the subject matter or materials discussed in the manuscript apart from those disclosed.

Medical writing and editing services were provided by Vanessa Marfil Vives and were funded by MSC (Medical Statistics Consulting, Valencia, Spain).

\section{Open access}

This work is licensed under the Attribution-NonCommercial-NoDerivatives 4.0 Unported License. To view a copy of this license, visit http://creativecommons.org/licenses/by-nc-nd/4.0/

\section{References}

1. Gregory C, Cifaldi M, Tanner LA. Targeted intervention programs: creating a customized practice model to improve the treatment of allergic rhinitis in a managed care population. Am. J. Manag. Care 5(4), 485-496 (1999).

2. Bousquet J, Khaltaev N, Cruz AA et al. Allergic rhinitis and its impact on asthma (ARIA) 2008 update (in collaboration with the World Health Organization, GA(2)LEN and AllerGen). Allergy 63(Suppl. 86), 8-160 (2008).

3. Calderon MA, Linneberg A, Kleine-Tebbe J et al. Respiratory allergy caused by house dust mites: what do we really know? J. Allergy Clin. Immunol. 136(1), 38-48 (2015).

4. Holgate S, Bisgaard H, Bjermer L et al. The brussels Declaration: the need for change in asthma management. Eur. Respir. J. 32(6), 1433-1442 (2008).

5. Marple BF, Fornadley JA, Patel AA et al. Keys to successful management of patients with allergic rhinitis: focus on patient confidence, compliance, and satisfaction. Otolaryngol. Head Neck Surg. 136(Suppl. 6), S107-S124 (2007).

6. Bousquet J, Lockey R, Malling HJ. Allergen immunotherapy: therapeutic vaccines for allergic diseases. A WHO position paper. J. Allergy Clin. Immunol. 102(4 Pt 1), 558-562 (1998).

7. Roger A, Depreux N, Jurgens Y, Heath MD, Garcia G, Skinner MA. A novel and well tolerated mite allergoid subcutaneous immunotherapy: evidence of clinical and immunologic efficacy. Immun. Inflamm. Dis. 2(2), 92-98 (2014).

8. Roger A, Depreux N, Jurgens Y et al. A novel microcrystalline tyrosine-adsorbed, mite-allergoid subcutaneous immunotherapy: 1-year follow-up report. Immunotherapy 8(10), 1169-1174 (2016).

9. Pfaar O, Demoly P, Gerth Van Wijk R et al. Recommendations for the standardization of clinical outcomes used in allergen immunotherapy trials for allergic rhinoconjunctivitis: an EAACI position paper. Allergy 69(7), 854-867 (2014).

10. Hauk L. Treatment of seasonal allergic rhinitis: a guideline from the AAAAI/ACAAI joint task force on practice parameters. Am. Fam. Physician 97(11), 756-757 (2018).

11. Dordal MT, Lluch-Bernal M, Sanchez MC et al. Allergen-specific nasal provocation testing: review by the rhinoconjunctivitis committee of the Spanish Society of Allergy and Clinical Immunology. J. Investig. Allergol. Clin. Immunol. 21(1), 1-12 quiz follow 12 (2011).

12. Valero A, Izquierdo I, Sastre J et al. ESPRINT-15 questionnaire (Spanish version): reference values according to disease severity using both the original and the modified ARIA classifications. J. Investig. Allergol. Clin. Immunol. 23(1), 14-19 (2013).

13. Atkinson MJ, Sinha A, Hass SL et al. Validation of a general measure of treatment satisfaction, the Treatment Satisfaction Questionnaire for Medication (TSQM), using a national panel study of chronic disease. Health Qual. Life Outcomes 2, 12 (2004).

14. Stelmach I, Kaczmarek-Wozniak J, Majak P et al. Efficacy and safety of high-doses sublingual immunotherapy in ultra-rush scheme in children allergic to grass pollen. Clin. Exp. Allergy 39(3), 401-408 (2009).

15. Kramer MF, Heath MD. Aluminium in allergen-specific subcutaneous immunotherapy-a German perspective. Vaccine 32(33), 4140-4148 (2014).

16. Bell AJ, Heath MD, Hewings SJ, Skinner MA. The adsorption of allergoids and 3-O-desacyl-4'-monophosphoryl lipid A (MPL(R)) to microcrystalline tyrosine (MCT) in formulations for use in allergy immunotherapy. J. Inorg. Biochem. 152, 147-153 (2015).

17. Baldrick P, Richardson D, Wheeler AW. Review of L-tyrosine confirming its safe human use as an adjuvant. J. Appl. Toxicol. 22(5), 333-344 (2002).

18. Gunawardana NC, Durham SR. New approaches to allergen immunotherapy. Ann. Allergy Asthma Immunol. 121(3), 293-305 (2018).

19. Purello-D'ambrosio F, Gangemi S, Merendino RA et al. Prevention of new sensitizations in monosensitized subjects submitted to specific immunotherapy or not. A retrospective study. Clin. Exp. Allergy 31(8), 1295-1302 (2001). 
20. Pajno GB, Barberio G, De Luca F, Morabito L, Parmiani S. Prevention of new sensitizations in asthmatic children monosensitized to house dust mite by specific immunotherapy. A six-year follow-up study. Clin. Exp. Allergy 31(9), 1392-1397 (2001).

21. Moller C, Dreborg S, Ferdousi HA et al. Pollen immunotherapy reduces the development of asthma in children with seasonal rhinoconjunctivitis (the PAT-study). J. Allergy Clin. Immunol. 109(2), 251-256 (2002).

22. Niggemann B, Jacobsen L, Dreborg $S$ et al. Five-year follow-up on the PAT study: specific immunotherapy and long-term prevention of asthma in children. Allergy 61(7), 855-859 (2006).

23. Olsen OT, Larsen KR, Jacobsan L, Svendsen UG. A 1-year, placebo-controlled, double-blind house-dust-mite immunotherapy study in asthmatic adults. Allergy 52(8), 853-859 (1997).

24. Yukselen A, Kendirli SG, Yilmaz M, Altintas DU, Karakoc GB. Two year follow-up of clinical and inflammation parameters in children monosensitized to mites undergoing subcutaneous and sublingual immunotherapy. Asian Pac. J. Allergy Immunol. 31(3), 233-241 (2013).

25. Incorvaia C, Barberi S, Pastorello E, Ciprandi G. The growing importance of real-life studies in allergen immunotherapy. Eur. Ann. Allergy Clin. Immunol. doi:10.23822/EurAnnACI.1764-1489.84 (2019) (Epub ahead of print).

26. Canonica GW, Baena-Cagnani CE, Bousquet $\mathrm{J}$ et al. Recommendations for standardization of clinical trials with Allergen Specific Immunotherapy for respiratory allergy. A statement of a World Allergy Organization (WAO) taskforce. Allergy 62(3), 317-324 (2007).

27. Bousquet J, Neukirch F, Bousquet PJ et al. Severity and impairment of allergic rhinitis in patients consulting in primary care. J. Allergy Clin. Immunol. 117(1), 158-162 (2006).

28. Benninger MS, Benninger RM. The impact of allergic rhinitis on sexual activity, sleep, and fatigue. Allergy Asthma Proc. 30(4), 358-365 (2009).

29. Blanc PD, Trupin L, Eisner M et al. The work impact of asthma and rhinitis: findings from a population-based survey. J. Clin. Epidemiol. 54(6), 610-618 (2001).

30. De La Hoz Caballer B, Rodriguez M, Fraj J, Cerecedo I, Antolin-Amerigo D, Colas C. Allergic rhinitis and its impact on work productivity in primary care practice and a comparison with other common diseases: the Cross-sectional study to evAluate work Productivity in allergic Rhinitis compared with other common dIseases (CAPRI) study. Am. J. Rhinol. Allergy 26(5), 390-394 (2012).

31. Advocacy Manifesto. Tackling the Allergy Crisis in Europe - Concerted Policy Action Needed. (2019). www.eaaci.org/documents/EAACI_Advocacy_Manifesto.pdf

32. Lee JH, Kim SC, Choi $\mathrm{H}$ et al. A retrospective study of clinical response predictors in subcutaneous allergen immunotherapy with house dust mites for allergic rhinitis. Allergy Asthma Immunol. Res. 10(1), 18-24 (2018).

33. Moreno C, Cuesta-Herranz J, Fernandez-Tavora L, Alvarez-Cuesta E. Immunotherapy Committee SEAIC. Immunotherapy safety: a prospective multi-centric monitoring study of biologically standardized therapeutic vaccines for allergic diseases. Clin. Exp. Allergy 34(4), 527-531 (2004).

34. Calderon MA, Alves B, Jacobson M, Hurwitz B, Sheikh A, Durham S. Allergen injection immunotherapy for seasonal allergic rhinitis. Cochrane Database Syst. Rev. doi:10.1002/14651858.CD001936.pub2(1), CD001936 (2007). 